\title{
A AGRICULTURA FAMILIAR E AS CAUSAS QUE GERAM O ÊXODO RURAL
}

Rafael Vinícius de Arruda, Victória Pontes Damasceno Araújo

Graduados em Agronomia pela Unic - Universidade de Cuiabá-MT

(raffabarao65@gmail.com)

\section{Recebido em: 06/04/2019 - Aprovado em: 10/06/2019 - Publicado em: 30/06/2019} DOI: 10.18677/EnciBio_2019A1

\begin{abstract}
RESUMO
Neste trabalho de releitura bibliográfica a finalidade foi compreender de maneira geral a forma com que a agricultura familiar contribui economicamente com as pequenas comunidades localizadas em grandes centros, e discutir o conceito e a importância da mesma no fortalecimento dos atributos sociais, ambientais e culturais das pequenas comunidades. Objetivando também apresentar as dificuldades atuais enfrentadas pelos agricultores para se conseguir acesso às políticas públicas rurais, escassez de assistência técnica, dificuldades na obtenção e excesso de burocracias e exigências bancárias para dar entrada em financiamentos de programas governamentais. Busca-se demonstrar as variadas formas de escoamentos de produtos e alguns dos obstáculos vividos pelos produtores rurais no momento de escoar suas mercadorias. Contudo, para que a agricultura familiar não se desfragmente com o passar dos anos, deve-se haver a união dos agricultores na intenção de fortalecer a classe para que haja um avanço no crescimento e fortificação da economia regional, e no fomento dessa união o crescimento passe a ser nacional.
\end{abstract}

PALAVRAS-CHAVE: Dificuldades; Escoamento; Política.

\section{FAMILY AGRICULTURE AND THE CAUSES THAT GENERATE THE RURAL EXODUS}

\begin{abstract}
In this work of bibliographical re-reading the purpose is to comprehend in a general way the way in which family farming contributes economically to small communities located in large centers, and to discuss the concept and importance of it in strengthening the social, environmental and cultural attributes of small communities. The objective is also to present the current difficulties faced by farmers in obtaining access to rural public policies, a shortage of technical assistance, difficulties in obtaining and excessive bureaucracy, and bank requirements for funding of government programs. It seeks to demonstrate the various forms of product flows and some of the obstacles experienced by rural producers when they ship their goods. However, if family farming is not to be defaced over the years, there must be a union of farmers with the intention of strengthening the class so that the growth and fortification of the regional economy can flourish, and in fostering this union growth become national.
\end{abstract}

KEYWORDS: Difficulties; Outlets; Politics. 


\section{INTRODUÇÃO}

A Agricultura Familiar é um modo de convivências sociais, culturais, ambientais e econômicas, na qual são executadas práticas agrícolas e pecuárias em bases familiares, desenvolvidas em estabelecimentos rurais ou em áreas comunitárias próximas aos centros das cidades. São administradas por famílias que expressam papéis significativos em prol do crescimento do país (BIANCHINI et al., 2016).

A Organização das Nações Unidas (ONU) predisse que até o fim do século serão 10 bilhões de habitantes (NORONHA , 2013). Esse fator impõe a expansão da produção de alimentos para atender essa quantidade populacional de maneira sustentável. Nos moldes adequados aos valores da agricultura familiar, que sofre devido à ausência de apoio governamental (SOUSA, 2017).

Os trabalhos desenvolvidos nas comunidades agrárias brasileiras são de importância fundamental para a economia do país, essencialmente, na contemporaneidade, para as pequenas comunidades, tanto na forma de fornecimento de alimentos, como gerando ocupação e renda. Porém, com o upgrade dado pela agricultura, seus produtos cujos valores se apresentam ineficiente frente aos do moderno capitalismo (DE AQUINO, 2017).

Segundo Candiotto (2011), no Brasil, o termo agricultura familiar ganhou visibilidade a partir da década de 1980. Entretanto, agricultores imaginavam que, com a vinda da visibilidade para a modalidade do plantio em família, poderiam ampliar o trabalho em suas propriedades com o auxílio de políticas públicas, aumentando a renda vinda de produção e do escoamento dos seus produtos para mercados urbanos, feiras locais e outros. Mas estão vivendo uma realidade contrária, desmotivados a continuar a vida no campo, estão abandonando as lavouras e saindo a procura de outras fontes de renda. Em consequência disso, acaba ocorrendo à fragmentação e a decomposição social e econômica da agricultura familiar.

Partindo desses pressupostos, este trabalho de pesquisa bibliográfica teve como objetivo compreender de maneira geral a forma com que a agricultura familiar contribui economicamente com as pequenas comunidades localizadas em grandes centros, e descrever a realidade voltada às dificuldades frente às políticas públicas e relatar as formas de escoamento das mercadorias agrícolas oriundas de comunidades.

Para esta pesquisa, foram utilizadas as plataformas Science, Google acadêmico e Scopus. Dentro das bases foram feitas utilizando os seguintes termos: agricultura familiar, políticas públicas, dificuldades em acesso ao crédito rural, formas de escoamento de alimentos, e selecionados 53 artigos e destes foram extraídas as informações necessárias para a execução deste trabalho.

\section{Agricultura Familiar nos Grandes Centros}

Conforme a Organização das Nações Unidas para Alimentação e Agricultura (FAO), a Agricultura familiar vem desenvolvendo um papel de suma importância para com o papel social, econômico, ambiental e cultural humano. E pode ser definida como o núcleo de organização das produções agrícola, pesqueira, pastoril, florestal e aquícola. Onde são administradas e conduzidas por uma família (FAO, 2014).

$\mathrm{Na}$ agricultura o Brasil se destaca diante dos outros países por ser um dos maiores produtores e exportadores de alimento e matéria prima. Porém agricultores 
familiares que alimentam suas regiões e até mesmo o país estão gerando "riquezas invisíveis" diante do esboço da economia (DELGADO; BERGAMASCO, 2017).

Parece, pois, ser inquestionável a relevância da agricultura familiar no processo de desenvolvimento rural. Seu potencial na atualidade vai além da produção de alimentos. É mais do que um modelo de economia agrária, consiste em um modelo de produção que são gerenciados e operados por uma família. É de suma importância para a comunidade, pois permite alavancar a economia local e por meio desta, melhorar a qualidade de vida da sociedade (WANDERLEY, 1999).

$\mathrm{Na}$ data de 24 de julho de 2006, a agricultura familiar foi reconhecida por lei, a qual estabeleceu as diretrizes da política nacional para o setor e para os estabelecimentos rurais quando sancionada a LEI № 11.326 (VALENTINI; VIEIRA, 2018). Os efeitos desta Lei vieram para considerar como agricultores familiares os que preenchessem os seguintes quesitos: não devem ter áreas maiores que quatro módulos fiscais e não possua qualquer título; os trabalhos agrários devem ser exclusivamente realizados pela respectiva família; renda predominantemente vindas das ações econômicas executadas pelos meios familiares; possuam uma porcentagem mínima da renda familiar vinda de atividades governadas pelo poder executivo; liderem sua propriedade com o apoio e companhia de sua família (VALENTINI; VIEIRA, 2018).

Souza (2006) conceitua o agricultor familiar ou empreendedor agrário como sendo aquele que pratica atividades no meio rural e que portam em seus conjuntos de práticas, técnicas de natureza econômica, social e ambiental, ligados à realidade e finalidade do seu sistema de produção.

Mesmo sendo responsável por mais de $70 \%$ da produção de alimentos do país, ser a base econômica de cerca de $90 \%$ dos municípios, conservando a paisagem rural ocupada e produtiva (mesmo que em menor grau), a agricultura familiar brasileira depara-se com dificuldade em responder aos desafios de maior competitividade da agricultura interna e globalizada (DOS SANTOS; MITJA, 2016).

A agricultura familiar não é um modelo central de desenvolvimento rural no

Brasil, com isso é incomum agricultores familiares terem salário fixo. Possuem ganhos a partir da venda do que produzem. Mesmo considerando uma menor proporção de terras, as empresas familiares ocupam de forma diversificada os pequenos espaços, com proporção maior por área cultivada, e assim fazendo com que gere mais trabalho e renda (COSTA et al., 2015).

\section{Aspectos ambientais}

A cultivação familiar é identificada como uma atividade dependente da natureza, essa dependência ocorre pelo fato do agricultor tirar desta todas as condições necessárias para a manutenção da vida, dentre os fatores necessários pode-se citar o solo, clima, água (MORAES; SANT'ANA, 2015). Estes autores continuam argumentando que na atualidade a agricultura tende a ser progressivamente influenciada por um complexo de pressões que emanam do relacionamento com o meio ambiente. Pelo fato dos agricultores optarem pelo desenvolvimento de atividades mais sustentais, tendem a fazer utilização de baixas quantidades de agrotóxicos e insumos; cultivos de alimentos tradicionais; ter produção em pequena escala, e que conforme os autores, a agricultura familiar apresenta grande mérito quando se trata de questão ambiental, principalmente por proporcionar alimentos saudáveis e segurança alimentar. 
Em conformidade com Primavesi (1997) os agrossistemas familiares dispõem de uma vocação para o desenvolvimento de práticas sustentáveis. Mais tarde, seguindo a linha de pensamento de Primavesti, os autores Finatto e Salamoni (2008) expõem que os agrossistemas possuem traços compatíveis com os princípios do progresso em pequenas propriedades que priorizam os pilares da sustentabilidade e que buscam novos sistemas produtivos, visando se adequar aos requisitos básicos sustentáveis.

Em resumo, através de uma agricultura diversificada com manejo que faça uso do sistema de poli cultivo, rotação de cultura, cultivo mínimo, sistemas agroflorestais, entre outras formas de manejo. Com isso o agricultor estará contribuindo de forma ativa na melhora do microclima local, na diminuição de insetos-pragas, patógenos e, estará contribuindo para a fertilidade do solo, particularidade da água e com natureza como um todo (DOMINGUES, 2016).

\section{Aspectos socioculturais}

A vida social local é oriunda do entrelaçamento de relações, as quais podem ser identificadas como: parentais e vizinhanças, relações essas que são à base da vida social do lugar em que exercem trabalhos, lazer e vida religiosa. O termo família do campo é expresso nos hábitos sociais que promovem uma união entre patrimônio, trabalho e consumo dentro do ambiente familiar, orientando uma ideia de funcionamento específico. Não se tratando apenas de constatar as formas de reconhecimentos vindos dos frutos do próprio trabalho, mas de receber apoio dos seus membros familiares na tarefa coletiva, gerando assim estímulos para continuar no serviço de produzir (CANDIOTTO, 2015).

Há enfoques teóricos que buscam abordar as questões que ressaltam os aspectos culturais dentro da comunidade familiar. De acordo com Schneider (2016), povos que priorizam os bens culturais que lhes são herdados, são fortemente incentivados pelas relações de consanguinidade e parentesco a continuarem com os recursos materiais, valores culturais e simbólicos que definem a sua identidade e é o maior envolvimento social que torna o agricultor familiar mais integrado ao exercício de trabalhar para a família e com a família.

O ambiente rural reconhecido pela Lei № 11.326 (BRASIL, 2006) é entendido como um local de base para relações socioculturais, onde a família desenvolve atividades trabalhistas em coletivo, desenvolvendo e fortalecendo laços parentais, culturais, religiosos e acima de tudo, sociais. Além do mais, cria-se uma união externa com o negócio e a vida urbana, resultando no entrelaçamento que atravessa o espaço local, aumentando assim o vínculo social (SCHNEIDER, 2016).

\section{Políticas públicas voltadas à agricultura familiar}

O composto de políticas públicas direcionadas à agricultura familiar foram elaboradas pelo Estado brasileiro, a datar de meados dos anos 1990. Desde então, as iniciativas públicas para 0 progresso rural sofreram grandes e importantes mudanças. Tais transformações podem ser descritas em três gerações, a primeira ocorreu voltada a cumprir demandas de seguimentos sociais, organizando-os em sindicatos e movimentos sociais e sindicatos agrícolas. A Segunda geração política foi reconhecida pela criação e expansão de políticas de assistência social. E a geração terceira ligada à idealização de novos mercados para os víveres e atividades oriundos da agricultura familiar, dispondo foco a segurança alimentar e a sustentabilidade (GRISA; SCHNEIDER, 2015). 
As políticas públicas vieram com o desafio de construir um novo projeto a fim de desenvolver integralmente as comunidades do campo. Os projetos foram voltados pensando nas possibilidades exatas para tornar o trabalho rural como profissional; erradicar o trabalho escravo nas propriedades e fazer com que os direitos trabalhistas fossem assegurados na formalidade da lei; eliminar também o trabalho infantil com intuito de diminuir o índice de analfabetismo no país e, trazer novas oportunidades para mulheres que, até então, tinham seus trabalhos no plantio e no artesanato de forma desvalorizada (DA SILVA, 2017).

A participação da sociedade civil é fundamental não apenas no âmbito da formulação de políticas públicas, mas também na fiscalização de sua implementação. Além disso, a priorização de estratégias e o aprimoramento dos processos e instrumentos internos de gestão devem estar referendados pelos seus beneficiários para o êxito das políticas públicas (ASSIS et al., 2017).

Estas visam responder as precisões da sociedade, principalmente seus setores mais vulneráveis. Essas demandas são interpretadas por aqueles que exercem a administração pública, mas são influenciadas por uma agenda que se cria na sociedade civil até através da organização e mobilização social que é reconhecida institucionalmente. Entretanto, com o histórico de dificuldades para se seguir no desenvolvimento agrário brasileiro, no decorrer dos tempos, o Brasil sofreu com a falta de acesso às técnicas de engenharias e com assistência técnica voltada a agricultura familiar, houve baixa capitalização, contrariedades para se ter acesso a linhas de créditos oficiais do governo, sofreu com as diferenças produtivas entre as regiões e com dificuldades de ingresso nos mercados modernos (DE PAULA et al., 2014).

Estudos mostram que os agricultores encontram dificuldades para acessar crédito para investir em sistemas de produção diversificados. O principal obstáculo está na capacidade das agências bancárias para avaliar a rentabilidade desses sistemas de produção. A influência negativa do seguro agrícola sobre a diversidade é explicada pelo motivo da redução do risco, que é um fator importante na decisão do agricultor de diversificar a produção e também pelo fato das instituições bancárias exigirem garantias para o fornecimento de empréstimos, o que alguns agricultores não possuem (SAMBUICHI et al., 2016).

Agricultores familiares imploram por políticas públicas apropriadas que sirvam de vias para com os produtores nos pequenos empreendimentos, fixando-os no campo e contribuindo com a estrutura econômica regional. Evitando que aconteça o inchamento das cidades devido à multiplicação do êxodo rural (DOS SANTOS; JOHN, 2018).

\section{Programa nacional de fortalecimento da agricultura familiar (PRONAF)}

O Programa (PRONAF) foi criado em 1996, pois antes disso, pode se dizer que era inexistente algum tipo de política pública com alcance nacional, voltada aos agricultores familiares com a finalidade de atender a uma velha reinvindicação das organizações dos trabalhadores do campo. As quais solicitavam a formulação e a implantação de políticas precisas para o avanço rural em que abrangiam em âmbito nacional. Com ressalvas, os produtores junto com suas organizações e através de muitas lutas, desempenharam um papel decisivo na implantação do programa (MATTEI, 2014).

Segundo Mendes et al. (2016), esse programa possui quatro objetivos específicos, o primeiro é regularizar e ajustar as políticas públicas em conformidade 
com a realidade vivida pelos produtores; fazer com que tenham infraestruturas viáveis e com capacidade de melhorar o desempenho na produção agrícola, profissionalizar agricultores e seus familiares através de acesso aos meios tecnológicos, com intuito de torná-los aptos aos novos padrões de inovação e estimulá-los a adentrarem nos mercados de produtos agrícolas e insumos.

Entretanto, a dificuldade parece estar na natureza da política agrícola que se pretendia estimular que, de forma redundante, apenas visava a incluir os até então excluídos, no mesmo modelo de desenvolvimento dominante, que os havia excluído. $\mathrm{Na}$ primeira fase da implantação, o acesso ao crédito do Pronaf tendeu a se concentrar nos estados do Sul, especialmente, entre os agricultores com vínculos contratuais de fornecimento com agroindústrias, mais aptos a oferecerem as garantias exigidas pelo sistema bancário (WANDERLEY, 2017).

Assim, a intenção objetiva de atender mais amplamente os pequenos agricultores familiares, visando ampliar o acesso dos agricultores considerados "periféricos", majoritariamente presentes nas regiões Norte e Nordeste do País. O Pronaf adotou uma diferenciação dos públicos beneficiários, dividindo em grupos $A$, B, C, D e E. O grupo A é formado por agricultores de assentamentos da reforma agrária; Grupo B: pelos de baixa produção e pequeno potencial de aumento, e nesse grupo estão incluídos indígenas e quilombolas, os grupos C, D e E são constituídos por grandes produtores, que dispõem de melhores índices de renda bruta (MATTEI, 2014).

Em resumo, O Programa nacional de fortalecimento a agricultura familiar, representa a comprovação social dos Agricultores familiares por parte do Estado brasileiro. A classe que era o dobro de vezes mais marginalizado do que contemporaneamente em condições de acessos de benefícios de política pública agrícola (CORCIOLI; CAMARGO, 2016).

\section{Falta de assistência técnica}

Estudos realizados por Gomes et al. (2018) sobre o desenvolvimento rural, apontam que no Brasil a pesquisa agrícola e a assistência técnica são pautadas pela racionalidade produtiva do modelo agrícola de produção de commodities e orientadas pela difusão e transferência tecnológica. Assim, continuam pouco adequadas às realidades socioambientais da Agricultura Familiar e dos Povos e Comunidades Tradicionais.

Quando se fala sobre pequenos agricultores, diz respeito a dificuldades, e as dificuldades dos mesmos estão ligadas a alguns aspectos fundamentais como: pouco investimento nas áreas de cultivo; ausência de uma cultura associadas à adoção de modernização e déficit de capacitação (MAIA et al., 2016). Entretanto, para Castro (2015), a dificuldade é outra, o autor relata que a maior deficiência está em contratar assistência técnica para quando se trabalha em família. Ademais, a dimensão da estrutura técnica com enfoque para a agricultura familiar é pequena, os escritórios longe de pequenas comunidades, geralmente possuem apenas dois técnicos, com essa escassez de técnicos e abundância de agricultores, os valores das assistências se elevam e saem dos projetos padrões dos que necessitam.

O técnico de extensão rural é um profissional formado na maioria dos casos principalmente em instituições de ensino superior de engenharia agronômica, zootecnia, economia doméstica e engenharia florestal. Esse novo padrão de profissional agrícola não foi difundido por todo meio agrícola nacional. Ele foi adicionado principalmente para os agricultores rurais do ramo capitalista 
proprietários de grandes terras no agronegócio, e em menor proporção por outras áreas das propriedades rurais, tradicionalmente tiveram menos atenção do estado na configuração de políticas públicas voltadas para a sua evolução (CASTRO, 2015).

$\mathrm{Na}$ maioria das vezes, os órgãos estaduais tem pouca capacidade para atender os agricultores da categoria a implementarem uma parceria com os agricultores, projetos completos e bem adaptados as condições locais, simplificados, para atender e servir de liberação do crédito do Pronaf. Com uma análise mais detalhada das espécies vegetais e dos animais mais viáveis para cada agricultor, considerando seu perfil e experiência, definindo as tecnologias a serem utilizadas, entre outros aspectos proporcionais a necessidade dos casos, que na maioria das vezes não são levadas em consideração nesses projetos (CASTRO, 2015).

\section{Dificuldades para ter emissão da declaração de aptidão do PRONAF}

Para haver a inclusão dos agricultores familiares às políticas públicas devem necessariamente ter a Declaração e Aptidão ao Pronaf (DAP), que é um instrumento de identificação e asseguração na condição de agricultor familiar, o qual é emitido por meio de uma análise produtiva na propriedade do agricultor pela Empresa de Assistência Técnica e Extensão Rural (EMATER). Com essa identificação, o produtor passará por uma análise na finalidade de desenvolvimento de projeto para a propriedade sempre no início de cada ano, nesta poderá ter acesso a financiamentos em linhas de crédito com juros acessíveis existentes nessa entidade (SAMBUICHI et al., 2016).

Existem diversas etapas durante todo o procedimento de aquisição do documento, é a parte burocrática mais difícil. Essa etapa corresponde as análises do cadastro, e essa dificuldade se refere a pouca informação disponibilizada sobre o programa, em relação à documentação, o que deve se fazer, aonde deve ir, com quem deve falar, principalmente para os que tem dificuldades de acesso a informações (GUEDES; DE CARVALHO, 2017).

Dentre as partes mais importantes do cadastro de emissão da DAP, o Cadastro Ambiental Rural (CAR) se destaca burocraticamente, pois consiste em fazer o levantamento de informações georreferenciadas do imóvel rural delimitando as Áreas de Preservação Permanente, APP, reserva legal. Existem vários obstáculos, para a execução do CAR e uma é o acesso à internet em zonas rurais distantes e, ainda, pela pouca informação disponibilizada sobre a finalidade do cadastro (NETO; DE MELO, 2016).

Boa parte de produtores passam pela análise da DAP, porém a maioria é barrada na etapa "crédito rural" do PRONAF por não conseguirem uma garantia satisfatória exigida pelos instrumentos financeiros, que solicitam garantias como empenho do imóvel rural e que possuam avalistas. Não atendendo a esses requisitos, terão os projetos com "aplicações consideradas de risco". Assim, os agricultores deixam de obter as rendas institucionais devido a esses fatores estipulados pelos responsáveis por concessão dos empréstimos (SPANEVELLO et al., 2016).

\section{Dificuldades na obtenção de créditos rurais}

A política de crédito rural no Brasil foi o principal meio de fomento à modernização conservadora ocorrida em meados dos anos 1960. Algumas leis encaminhadas pelo Poder Executivo durante o Regime Militar (1964 a 1985) deram 
suporte a este processo de modernização da agricultura brasileira. Em resumo pode-se destacar a Lei do Estatuto da Terra, Lei n. 04.504 de 30 de novembro de 1964, que regula os direitos e as obrigações dos proprietários de imóveis rurais para fins de execução da Reforma Agrária e para a promoção da Política Agrícola (BIANCHINI, 2015).

Atualmente no Brasil há uma enorme população rural empobrecida, que não são integrados aos eventos relevantes de empresas, agências estaduais, organizações agrícolas sindicais e sociais que trabalham para captar recursos financeiros e projetos de desenvolvimento agrário. Com isso, esses projetos, como as linhas de créditos, acabam sendo encaminhados especialmente para os que possuem melhores e maiores condições técnicas e econômicas para a classe rural realizar trabalhos (GRISA; SCHNEIDER, 2015).

Diniz (2016) relatou que a existência da divisão em âmbito rural, a qual se dá por existir um lado pertencente aos agricultores familiares decaídos, e outro aos grandes e privilegiados políticos, com a facilidade de ter acesso às formas de financiamentos. As exclusões para com os agricultores empobrecidos ocorrido devido à existência de dificuldade na obtenção de crédito. As exigências são extremamente complexas na hora de abrir contas ou acessar alguma linha específica. Com isso não são contemplados e, consequentemente, os planos de investimentos nos seus empreendimentos familiares acabam ficando apenas na vontade.

Com início da aplicação da correção monetária conforme se fazia os empréstimos que acompanhava, os índices de inflações atuais tiveram muitos impactos nos resultados dos produtores. Em relação ao programa, encontra-se um expressivo aumento na taxa de inadimplência dos contratos realizados, em consequência, os produtores não estavam conseguindo ver a compatibilidade na evolução dos valores agrícolas, em função das taxas e juros cobrados (BIANCHINI, 2015).A organização de concessão de crédito vem sofrendo constantes mudanças desde o início da política de crédito de custeio e investimento, principalmente no que se diz respeito aos valores de financiamentos, assim como se refere às taxas de juros que acometem sobre os recursos concedidos ao programa (BIANCHINI, 2015).

Essas complicações vêm de longas datas, constata-se nos registros que durante o curso da modernização da agricultura brasileira (nos decênios 60 e 70), as políticas públicas criadas para a área rural, em especial a política agrícola, foram privilegiados os setores mais capitalizados, os que teriam a esfera de produção monocultura de commodities. Para os cultivadores familiares, a repercussão dessas políticas foi profundamente negativa, já que os grandes ficaram com os benefícios oferecidos pela política agrícola, acima de tudo no tocante ao crédito rural, preços mínimos e seguro de produção (MATTEI, 2014).

Em relato, Wanderley (2000) expõe enfatizando o espaço rural de não possuir homogeneidade. Para a autora, cada região recebe apoio diferenciado, tendo assim, locais privilegiados superiormente relacionados a outros, e essa heterogeneidade acontece pelo fato de um determinado local predominar grandes monoculturas e outros, pequenas policulturas. Contudo, os apoios das políticas de crédito acabam sendo destinados com maior facilidade para os que irão representar maiores garantias de pagamentos dos benefícios recebidos dos agentes financiadores, sobrando assim, a contínua precariedade para os pequenos agricultores.

Para Lima e Shirota (2005), deve-se ter um sistema financeiro eficiente, com menores taxas e, o que é particularmente importante no crédito rural, com maior 
volume de recursos, deve realizar transações a custo mínimo. Isto depende do sucesso na avaliação das alternativas de investimentos e no direcionamento dos recursos disponíveis para estes, além do monitoramento dos tomadores. A intermediação financeira deve proporcionar o uso eficiente dos recursos (escassos) disponíveis.

\section{As diferentes formas de escoamento de produtos e dificuldades no momento de escoar}

A mercantilização da agricultura familiar é caracterizada pelo escoamento de produtos em diversificados canais de mercado, tais como: vendas diretas para consumidores; cooperativas; intermediário - atravessador; agroindústria ou empresa privada; venda direta em feiras livres; para o poder público-município; armazém ou venda na localidade (DE SANTANA, 2011). A seguir estão alguns exemplos de canais de mercado.

A esfera varejista vem se tornando a união mais importante de distribuição de alimentos perecíveis, pois os supermercados têm os principais canais de distribuição de frutas, verduras e hortaliças nos grandes centros (RETIÉRE, 2014). Segundo a autora, o mercado brasileiro é regulado através de contratos informais, baseados na concessão de vantagens, pelos produtores e donos de mercados envolvidos na transação. No entanto, os contratos informais limitam a expansão dos produtores com seus produtos adiante os limites dos municípios.

Com o aumento dos supermercados, passou se a observar a queda da comercialização de produtos frescos em feiras livres. Na óptica de Faulin e Azevedo (2003), isso se deu pelo fato da mudança de hábitos dos consumidores. Umas das mudanças foi o aumento da presença de mulheres nas atividades, ocasionando assim a diminuição do tempo médio disponível para ter que frequentar o supermercado e a feira para poder cumprir as necessidades de compras.

Atualmente, mesmo com a pouca valorização voltada às feiras livres, os agricultores familiares não deixam de montar barracas, nas quais trabalham pais, irmãos, primos que sustentam os hábitos vindos tradicionalmente de seus antecessores. Com isso mantem traços históricos de plantar, cuidar, colher e vender em localidades ou regiões próximas, mantendo assim os traços históricos de suas origens (SAMBUICHI et al., 2014).

Podem também serem escoados para Cooperativas, que são entidades jurídicas que tem o papel social e econômico para a introdução do setor produtivo no mercado (CORCIOLI; CAMARGO, 2016). Semelhantes a associações que tem administração coletiva e democrática. Segundo Minatel e Bonganha (2015) os agricultores se unem para a formação de cooperativas com foco em melhores resultados. Juntando os produtos, conseguem mais mercadorias para a venda, e tendo mais operários envolvidos. Por isso, conseguindo agregar maiores valores em suas mercadorias.

A instituição mercantil alimentícia, em sua extensão, é o setor que envolve pelo menos uma das três esferas governamentais (municipal, estadual e federal) e em todas as operações que compra os alimentos. Nessas operações podem ter aptidão contínua em atendimento por meio das compras dessa natureza, as escolas, creches e hospitais (DE PAULA et al., 2014).

O escoamento para mercados institucionais é o escoamento de alimentos diretamente ou por meio de cooperativas, sem licitação, para as escolas, creches ou outros órgãos públicos municipais. Esse tipo de venda acontece com o auxílio de 
programas e instrumentos governamentais com o intuito de fomentar a agricultura familiar. Em esfera Federal, foram criados programas governamentais para auxiliar no escoamento de produtos de agricultores familiares e esses programas garantem a comercialização dos produtos agropecuários (DE PAULA et al., 2014).

A construção do mercado é a principal dificuldade dos produtores familiares (REDIN, 2013). Para este autor, é notório que os agricultores familiares não possuem aguçada visão de autonomia para fazer a construção de seus próprios espaços de comercialização de produtos. Isso ocorre pelo fato dos mesmos não entenderem que a função deve ser a de construir as próprias oportunidades de comércio, exercendo assim, o papel de plantar, colher e finalizar o ciclo com êxito no momento de escoar.

\section{Agroindústrias para agregação de valores aos produtos}

É crescente, na contemporaneidade, a demanda por ampliar e fazer com que a propriedade se desenvolva e cresça em meio aos até então "pequenos agricultores". Vendo empresas multinacionais se expandindo e tendo os produtos com preços elevados, agricultores juntos de suas famílias buscando alternativas para a agregação de valores aos seus produtos, com isso optam pelas agroindústrias familiares, as quais possuem papel importante para o produtor rural, principalmente, o de pequena escala de produção (SILOCHI et al., 2013).

As agroindústrias são compreendidas como meio de transformação de produtos provenientes de trabalhos agrícolas em geral, e abrange processos simples e complexos, e se agrupam em funções de secagem, classificação, beneficiamento como um todo e até embalagem, e as atividades mais complexas são as operações química, física, biológica e até mesmo mecânica, como a extração de óleo (HARTWIG; VENDRAMINI, 2018).

Os autores Machado et al. (2016) afirmam que os aspectos que centralizam a viabilização de intensificação das agroindústrias rurais são causas relacionadas aos trabalhadores agrícolas, que utilizam seus próprios recursos de produção para produção, tais como: força de trabalho; processos artesanais; escala de produção que é classificada como pequena, e o maior cuidado com os alimentos e decorre também do fato do saber-fazer enraizado em meio cultural regional. Essas características são importantes para a elaboração de produtos agroindustriais diferenciados, pois se quando comparado aos produtos da grande distribuição agroalimentar, os produtos agro industrializados pelos pequenos agricultores serão beneficiados comercialmente pelo fato de receberem a tarja de alimentos agroecológicos, e com isso aumentará a proporção de acesso a mercados específicos que garantem maior margem de valor adicionado.

Entretanto, as maiores dificuldades são encontradas nas rígidas exigências sanitárias postas para a comercialização de produtos de origem animal, exigências essas que não são adaptadas à realidade dos pequenos produtores familiares (MORETTO, 2018). Para Perufo et al. (2017) a rigidez dos serviços de inspeção sanitária é enorme para se conseguir retirar alvará para processar produtos, inviabilizando assim os produtores de venderem seus produtos de forma licenciada diretamente para os mercados, feiras, açougue, com valores compensativos e os submetendo a entregar os seus produzidos para atravessadores que pagarão preços muito baixos, mas que mesmo assim é a única forma dos agricultores escoarem os alimentos sem que os mesmos fiquem nas propriedades sem serem vendidos. 


\section{CONSIDERAÇÕES FINAIS}

A agricultura familiar vem ganhando destaque ao longo dos anos, e para continuar se destacando no mundo do agronegócio dependerá do contínuo processo de fortalecimento e valorização através do desenvolvimento de um conjunto de fatores que englobem razões sociais, culturais, políticas e econômicas.

Uma das grandes dificuldades ainda são as políticas públicas que não atendem as específicas necessidades de algumas famílias produtoras, com isso, diminui a permanência das mesmas no campo, pois ainda que o governo ofereça programas como o Pronaf, que oferece linhas de crédito e projeto de assistência técnica aos agricultores, até então não é suficiente, já que não abrange a todos os agricultores familiares da mesma forma. A falta de regularização das propriedades estabelece ainda mais a dificuldade, pois não consegue obter os documentos necessários, impossibilitando assim o seu acesso.

E como forma de facilitar o acesso ao crédito rural para agricultores familiares, deve-se aumentar a divulgação das linhas de crédito do PRONAF com suas especificidades; criar linha de crédito estadual para facilitar a parte burocrática do processo de obtenção; ampliar a oferta de microcrédito para empreendimentos rurais; articular e capacitar agentes financeiros públicos, privados e agentes da ATER para facilitar e promover o acesso ao crédito rural; fortalecer e incentivar os pequenos agricultores a irem à busca da autonomia financeira e empoderamento das mulheres e dos jovens do campo.

O problema de escoamento da produção se dá devido à falta de visão e organização dos produtores para com os sistemas de distribuição, já que a maior parte tem a cultura de plantar em pequenas escalas, grande diversidade de produtos, e consequentemente a dispersão de produtos em pequenos lotes acaba dificultando a composição da carga. Como outros produtores da região possuem a mesma cultura de diversificação de produtos, compradores irão às propriedades que Ihes oferecer menores preços, pois os mesmos tem ciência de que por questão de sobrevivência os agricultores familiares são imediatistas, e assim irão vender por preços baixos, independente de lucros, só para não perderem a produção. Sendo que o sistema familiar engloba diversas atividades agrícolas na inserção nos circuitos de comercialização se observa o beneficiamento dos produtos.

Dessa forma, se tratando de inserção nos circuitos de comercialização, é possível observar diversos entraves enfrentados pelos agricultores familiares que vão desde o beneficiamento dos produtos nas agroindústrias, questões fiscais, tributárias e sanitárias, aos espaços para efetivar a venda ao consumidor e para isso sugere-se criar regime tributário especial de incentivos para produtores agro industrializado e de extrativismo sustentável oriundos de associações e cooperativa da Agricultura Familiar, e apoiar o desenvolvimento de cadeias de gastronomia regional e artesanato, com ênfase na participação de povos e comunidades tradicionais e assentados da reforma agrária.

Contudo, a principal causa de tais problemas é a desunião por parte da categoria na busca por objetivos específicos citados ao longo do trabalho como forma de complicações, e o processo para reverter essa situação é a criação de programa de apoio ao associativismo e cooperativismo para gestão de empreendimentos rurais, formando e capacitando em ordem produtiva a gestão de empreendimentos e formação de novas lideranças. 


\section{REFERÊNCIAS}

ASSIS, S.C.R.; PRIORE, S.E.; FRANCESCHINI, S.C.C.C. Impacto do Programa de Aquisição de Alimentos na Segurança Alimentar e Nutricional dos agricultores. Ciência \& Saúde Coletiva, v. 22, p. 617-626, 2017.

BIANCHINI, P. C.; TAKAGI, M.; PIRAUX, C.; TONNEAU, J.P.; BIANCHINI, F.; FERREIRA, M. A. J. F.; SILVA, P. C. G. da. Agricultura Familiar, Territórios e Políticas Públicas: Diretrizes para uma agenda de Pesquisa. 2016.

BIANCHINI, V.; Vinte anos do PRONAF, 1995-2015: avanços e desafios. Brasília: SAF/MDA, p. 45-68, 2015.

BRASIL. Lei no 11.326 de 24 de julho de 2006. Brasíli, DF, 2006. Disponível em: <http://www.planalto.gov.br/ccivil_03/_ato2004-2006/2006/lei//11326.htm>. Acesso em: 20 fev. 2019.

CANDIOTTO, L.Z.P.; Implicações do turismo no espaço rural e em estabelecimentos da agricultura familiar. Revista de Turismo y Patrimonio Cultural, v. 9, n. 4, p. 559$571,2011$.

CANDIOTTO, L.Z.P.; O discurso da viabilidade do turismo rural na agricultura familiar: o programa nacional de turismo rural na agricultura familiar (PNTRAF) e o papel do estado do Paraná no contexto. CULTUR-Revista de Cultura e Turismo, v. 7, n. 2, p. 111-131, 2015.

CASTRO, C.N. Desafios da agricultura familiar: o caso da assistência técnica e extensão rural. 2015.

CORCIOLI, G.; CAMARGO, R.S.; Programa Nacional de Fortalecimento da Agricultura Familiar (Pronaf). Agricultura Familiar em Goiás, p. 253, 2016.

COSTA, Bianca Aparecida Lima et al. As cooperativas de agricultura familiar e o mercado de compras governamentais em Minas Gerais. Revista de Economia e Sociologia Rural, v. 53, n. 1, p. 109-126, 2015.

DA SILVA, Nielsen Christianni Gomes. Documento técnico contendo propostas para o papel dos colegiados territoriais na articulaçô de políticas públicas para ações de desenvolvimento rural sustentável no semiárido. IICA, Brasília, DF (Brasil), 2016.

DE AQUINO, J.R.; FREIRE, J.A.; DE CARVALHO, A.C.AT. Importância, heterogeneidade e pobreza da agricultura familiar no estado do Rio Grande do Norte. Revista Geotemas, v. 7, n. 2, p. 66-92, 2017.

DELGADO, G.C.; BERGAMASCO, S.M.P.P. Agricultura familiar brasileira: desafios e perspectivas de futuro. Brasília: Ministério do Desenvolvimento Agrário, 2017. 
DE PAULA, M.M.; KAMIMURA, Q.P.;SILVA, J.L.G.; Mercados institucionais na agricultura familiar: dificuldades e desafios. Revista de Política Agrícola, v. 23, n. 1, p. 33-43, 2014.

DE SANTANA SOUZA, L.R.; A modernização conservadora da agricultura brasileira, agricultura familiar, agroecologia e pluriatividade: diferentes óticas de entendimento e de construção do espaço rural brasileiro. Cuadernos de Desarrollo Rural, v. 8, n. $67,2011$.

DINIZ, .M.A.; Migração e evolução da fronteira agrícola. Anais do XIII Encontro Nacional de Estudos Populacionais, p. 1-26, 2016.

DOMINGUES, O.; Preservação e seleção das raças nativas de gado do Nordeste. Brazilian Journal of Agriculture -Revista de Agricultura, v. 29, n. 7-9, p. 233-238, 2016.

DOS SANTOS, A.M.; MITJA, D.; Agricultura familiar e desenvolvimento local: os desafi os para a sustentabilidade econômico-ecológica na comunidade de Palmares II, Parauapebas, PA. Interações (Campo Grande), v. 13, n. 1, 2016.

DOS SANTOS, C.S.; JOHN, N.S.; O desenvolvimento rural e a agroecologia: uma alternativa para sustentabilidade ambiental/Rural development and agroecology: an alternative for environmental sustainability. Brazilian Journal of Development, v. 4, n. 6, p. 3053-3063, 2018.

EHLERS, E.; O que é agricultura sustentável. Brasiliense, 2017.

FAO, Food. Agriculture Organization, 2014. Cereal Supply and Demand Brief-5 July 2012, 2014.

FAULIN, E.J.; AZEVEDO, P.F.; Distribuição de hortaliças na agricultura familiar: uma análise das transações. Informações Econômicas, v. 33, n. 11, p. 24-37, 2003.

FINATTO, R.A.; SALAMONI, G.; Agricultura familiar e agroecologia: perfil da produção de base agroecológica do município de Pelotas/RS. Sociedade \& Natureza, v. 20, n. 2, p. 199-217, 2008. A, 1997. p. 180., 1997.

GOMES, D.; OEIRAS, G.; PORRO, R. Acesso diferenciado a políticas públicas em agricultores agroextrativistas do território do médio Mearim, Maranhão. In: Embrapa Amazônia Oriental-Artigo em anais de congresso (ALICE). In: CONGRESSO INTERNACIONAL DAS CIÊNCIAS AGRÁRIAS, 3., 2018, João Pessoa. Ciência, tecnologia e desenvolvimento rural: compartilhando conhecimentos inovadores e experiências. João Pessoa: Instituto Internacional Despertando Vocações, 2018., 2018.

GUANZIROLI, C.E.; PRONAF dez anos depois: resultados e perspectivas para o desenvolvimento rural. Revista de economia e sociologia rural, v. 45 , n. 2, p. 301 328, 2007. 
GUEDES, A.A.A.; DE CARVALHO, D.M.; Dificuldades e gargalos de acesso ao pronaf B em Garanhuns-PE. Revista Brasileira de Gestão e Desenvolvimento Regional, v. 13, n. 3, 2017.

GRISA, C.; SCHNEIDER, S.; Políticas públicas de desenvolvimento rural no Brasil. 2015. Disponível em; http://www.ufrgs.br/pgdr/publicacoes/livros/outraspublicacoes/politicas-publicas-de-desenvolvimento-rural-no-brasil acesso em abril/2019.

HARTWIG, M.; VENDRAMINI, C.R.; Trabalho coletivo na agricultura familiar integrada ao capital agroindustrial de fumo. Revista Trabalho Necessário, v. 6, n. 6, 2018.

LIMA, R.A.S.; SHIROTA, R.; Influência do capital social no mercado de crédito rural. Revista de Economia e Sociologia Rural, v. 43, n. 1, p. 63-80, 2005. LIMA, Roberto Arruda de Souza; SHIROTA, Ricardo. Influência do capital social no mercado de crédito rural. Revista de Economia e Sociologia Rural, v. 43, n. 1, p. 63-80, 2005.

MACHADO, L.F.; MUROFUSE, N.T.; MARTINS, J.T.;Trevisan. Vivências de ser trabalhador na agroindústria avícola dos usuários da atenção à saúde mental. Saúde em Debate, v. 40, p. 134-147, 2016.

MAIA, C.; FIDELES, J.; MEDINA, G.; Reforma agrária. Agricultura Familiar em Goiás, p. 228, 2016.

MATTEI, L.; O papel e a importância da agricultura familiar no desenvolvimento rural brasileiro contemporâneo. Revista Econômica do Nordeste, v. 45, n. 5, p. 83-92, 2014.

MEDINA, G.; NOVAES, E.; Percepção dos agricultores familiares brasileiros sobre suas condições de vida. Interações (Campo Grande), v. 15, n. 2, 2015.

MENDES, P.E.F.; BASTOS, R.G.; SOUZA, C.F.; Efluente tratado na agricultura: aspectos agronômicos e sanitários no cultivo do rabanete. Revista Brasileira de Agricultura Irrigada-RBAl, v. 10, n. 1, p. 428-438, 2016.

MINATEL, F.; BONGANHA, C.A.; Agronegócios: A importância do cooperativismo e da agricultura. Empreendedorismo, Gestão e Negócios, v. 4, n. 4, p. 247-259, 2015.

MORAES, M.D.; SANT'ANA, A.L.; Características Socioeconômicas do Assentamento Banco da Terra, Nova Xavantina (MT): uma análise sob a ótica da adoção ou construção de conhecimentos. Revista de Economia e Sociologia Rural, v. 53, n. 4, p. 589-606, 2015.

MORETTO, T.; Análise comparativa entre os sistemas de inspeção Estadual e Federal em uma agroindústria familiar do interior do estado do Rio Grande do Sul. 2018. Trabalho de Conclusão de Curso. 
NETO, E.S.F.T.; DE MELO, J.A.M.; Cadastro Ambiental Rural, CAR-Um Estudo sobre as principais dificuldades relacionadas a sua implantação. Negócios em Projeção, v. 7, n. 2, p. 54-68, 2016.

NORONHA, F. Terceiro mundo e Brasil no sistema mundial de interdependência complexa. $2013 . \quad$ Disponivel em; http://bdtd.ibict.br/vufind/Record/UFSC_5ba525a1a56a77a625dee8a5766d9a70 acesso em abril/2019

PERUFO, N.B.; DE MORAES BATISTA, L.; CORTEZ, N.K.; Agroindustrias familiares fabricantes de produtos cárneos suínos: Principais dificuldades perante a legislação vigente. Revista Destaques Acadêmicos, v. 10, n. 1, 2017.

PRIMAVESI, O.; PRIMAVESI, A. C. Taxa de degradação de material orgânico no solo, sob manejo de pastagens, agricultura e mata. In: Embrapa Pecuária SudesteResumo em anais de congresso (ALICE). In: Encontro Brasileiro sustâncias húmicas 2., 1997, São Carlos. Anais... São Carlos: EMBRAPA/CNPDI

REDIN, E.; Muito além da produção e comercialização : dificuldades e limitações da agricultura familiar. Perspectivas em Políticas Públicas, v. 6, n. 12, p. 111-151, 2013

RETIÉRE, M.I.H.. Agricultores inseridos em circuitos curtos de comercialização: modalidades de venda e adaptações dos sistemas agrícolas. 2014. Tese de Doutorado. Universidade de São Paulo.

SAMBUICHI, R.H.R.; SILVA, A.P.M.; OLIVEIRA, M.A.C.; SAVIAN, M.; Compras públicas sustentáveis e agricultura familiar: a experiência do Programa de Aquisição de Alimentos (PAA) e do Programa Nacional de Alimentação Escolar (PNAE). Políticas agroambientais e sustentabilidade: desafios, oportunidades e lições aprendidas. Brasília, DF: IPEA, p. 75-104, 2014.

Sambuichi, Regina Helena Rosa; Galindo, Ernesto Pereira; Pereira, Rodrigo Mendes; Constantino, Michel; dos Santos Rabetti, Matheus

SAMBUICHI, R.H.R.; GALINDO, E.P.; PEREIRA, R.M.; CONSTANTINO, M.S.R. et al., Diversidade da Produção nos Estabelecimentos da Agricultura Familiar no Brasil: uma análise econométrica baseada no cadastro da Declaração de Aptidão ao Pronaf (DAP). 2016.

SCHNEIDER, S. A presença e as potencialidades da agricultura familiar na América Latina e no Caribe. Redes: revista do desenvolvimento regional. Santa Cruz do Sul, RS. Vol. 21, n. 3, pt. 2 (set./dez. 2016), p. 11-43, 2016.

SILOCHI, R.M.H.Q.; DE SOUZA LIMA, R.; DE OLIVEIRA, I.C.; Agroindústria familiar: Experiência profissionalizante da Cooperativa da Agricultura Familiar Integrada (COOPAFI) em Francisco Beltrão-PR. Revista ELO-Diálogos em Extensão, v. 2, n. $1,2013$. 
SOUSA, M.S. ; Os programas de estímulo à agricultura familiar e o direito humano à alimentação adequada. 2017.

SOUZA, H.N.; Sistematização da experiência participativa com sistemas agroflorestais: rumo à sustentabilidade da agricultura familiar na zona da mata mineira. 2006. Tese de Doutorado. Universidade Federal de Viçosa.

SPANEVELLO, R.M.; MATTE, A.; BOSCARDIN, M.; Crédito rural na perspectiva das mulheres trabalhadoras rurais da agricultura familiar: uma análise do Programa Nacional de Fortalecimento da Agricultura Familiar (PRONAF). Polis. Revista Latinoamericana, n. 44, 2016.

VALENTINI, M.;C.; VIEIRA, A.C.P.; Desenvolvimento por meio de política pública de inserção dos agricultores artesanais no mercado do vinho: Lei do Vinho Artesanal. 2018.

WANDERLEY, M.N.B.; "Franja Periférica","Pobres do Campo",Camponeses": dilemas da inclusão social dos pequenos agricultores familiares. Agricultura Familiar Brasileira: Desafios e Perspectivas de Futuro, p. 66, 2017.

WANDERLEY, M.N.B.; Raízes históricas do campesinato brasileiro. Agricultura familiar: realidades e perspectivas, v. 3, p. 21-55, 1999.

WANDERLEY, M.N.B.; A valorização da agricultura familiar e a reivindicação da ruralidade no Brasil. Desenvolvimento e meio ambiente, v. 2, 2000. 